\title{
Ler o amor, pensar o amor
}

\section{Leandro Castro Oltramari*}

Professor da Universidade do Vale do Itajaí/UNIVALI - Itajaí, Santa Catarina, Brasil

\section{SOBRE O AMOR ( 175 páginas) \\ KONDER, L.}

São Paulo: Boitempo, 2007.

No alto de seus 70 anos, Leandro Konder já possui renomada carreira, autor de diversos artigos e livros, principalmente discutindo filosofia marxista. Agora ele surpreende a todos com uma obra não usual em seu currículo: desta vez ele escreve sobre o amor. Surpreende a temática que ele aborda, apesar de estar desde 2005 atuando em uma linha de pesquisa intitulada Arte, "engajamento" e educação. Não que sua maturidade intelectual não permita que ele escreva sobre o que bem entender, mas não é comum um autor reconhecido arriscar-se, nesta fase da vida intelectual, a investir em outras perspectivas teóricas. Konder mostra-se corajoso, pois se arrisca nesta empreitada.

Podemos identificar que seu texto, como ele mesmo aborda, não se propõe a conceituar o amor, muito menos a descrevê-lo a partir de uma cronologia delimitada por fatos históricos. Ele se propõe, a partir de diversos autores, a "passear" pelas suas trajetórias de vida, por vezes por suas vidas amorosas e por suas concepções de amor.

Ele tem a destreza de poder fazer leituras que vão de Platão ao contemporâneo brasileiro Carlos Drummond de Andrade. Claro que isso possibilita que o seu mérito seja grande, mas os riscos nos quais incorre Konder também. Tal tensão aparece em seu texto. Por vezes, a lógica do mesmo parece perder-se entre o que os autores pensam sobre o amor e o que ou a quem eles amaram. Isto traz certa confusão para quem está lendo. Mas, ao final da obra, compreende-se aonde ele quer levar seus leitores.

Inicia, como a ampla maioria de autores que discorrem sobre o amor, citando, de início, Platão e seu Banquete.Konder, a partir daí, aborda as várias facetas que o amor possui e sob as quais tem ocupado bastante 0 mundo ocidental. Talvez seja essa a razão pela qual o autor resolva escrever sobre o tema. Ele revela que existe uma tendência muito proeminente de se fazer relação ao amor como "algo cósmico" ou 
"mágico" na melhor tradição "romântica" citada já na obra clássica de Denis de Rougement intitulada História do amor no ocidente epublicada originalmente em 1939. Por isso ele já cita no início de seu trabalho que "a paixão jamais elimina completamente a participação da vontade do sujeito" (p.10), indicando claramente que não concorda com a idéia de que o amor tem uma relação de destino fatal, como muitas vezes é enunciado pelos amantes. Ele segue em sua obra uma lógica já aplicada por outros autores, como Eric Blondel na obra L'Amour, publicada em 1998, e que também aborda o pensamento de diversos autores, alguns inclusive igualmente citados por Konder. Entretanto, naquela obra, Blondel se preocupa em retirar pequenos extratos de textos originais dos autores para demonstrar seu pensamento. No texto de Konder, o que existe é uma leitura dele sobre o pensamento dos autores que ele escolheu para falar sobre o amor. Portanto, ele se propõe a discutir o conceito filosófico do Amor. Ao contrário de outros autores que vão ao encontro de tentar discutir o amor nas suas aplicações cotidianas, Konder deixa claro que não se preocupa com estas prerrogativas para escrever seu texto. O que temos, a partir de sua leitura, é uma discussão filosófica densa, que passa longe de textos "psicológicos" sobre o assunto.

Apesar disso, sua discussão por vezes oscila entre o conceito do "amor" e o sentimento amoroso a que denominamos pelo mesmo nome, assunto que já vem sendo debatido nos meios acadêmicos através de Bozon (2004) e de Gagnon (2006). Estes autores revelam que o amor, assim como a sexualidade, constitui formas de jogos sociais que se expressam na interação entre os sujeitos que se aproximam.

O autor avisa que, apesar dos riscos das vicissitudes do amor, ele se faz uma experiência necessária e não, como muitas vezes pode ser descrita, uma perda no campo da humanidade. Nestes casos, Konder parece um tanto "romântico" quando afirma que o amor é uma forma de os humanos procurarem um mundo melhor. Aqui vale uma reflexão. Em nenhum momento podemos identificar o pensador Zigmunt Bauman (2004) e sua discussão sobre o Amor Líquido. Konder, talvez por sua tradição e fidelidade ao pensamento marxista, nega, por exemplo, a discussão do amor sob a lógica da sua imaterialidade ou de transformações contínuas. Isto demonstra um distanciamento do pensamento de Bauman,o que poderia dar uma boa discussão teórica, pois sua análise poderia ter avançado, por exemplo, em discutir como as relações amorosas no mundo contemporâneo podem influenciar a literatura, construindo novos modelos de relacionamentos.

Entre tantos autores, citarei apenas alguns de quem ele traz a suas leituras, que vão de Sócrates a Simone de Beauvoir. Ele vai fazendo apontamentos sobre o que falaram e, muitas vezes, sobre como viveram seus amores. Sendo um misto de descrição filosófica e, por vezes, de 
características biográficas, o autor vai tecendo os comentários sobre grandes autores da literatura mundial.

Sobre Sócrates, ele cita o texto do Banquete. Neste texto, existe uma clara referência do interesse afetivo de Sócrates sobre Agatão. No banquete, os ilustres convidados falam sobre o amor. Segundo Konder, falando sobre a perspectiva da Mitologia Grega, o amor traz a "nostalgia de um tempo extremamente longínquo" (p. 14). Ele ainda revela que, no pensamento Platônico, os sujeitos esperam do amor o que eles já possuem. Ele exemplifica tal observação, inclusive, descrevendo a cena em que Alcebíades relata com destreza as vezes em que tentou envolver Sócrates em climas eróticos para satisfazer seu amor por ele.

Outro exemplo interessante que ele descreve não é nada mais que sua visão de amor sobre Marx, um autor do qual Konder tem profundo conhecimento. Ele, de início, já revela que dificilmente a palavra amor está relacionada ao autor. Mas, ainda assim, ele é citado sobre a discussão do tema. É claro que não é possível duvidar de que realmente Marx tenha, em algum momento de suas obras, falado sobre o amor. É bem provável que sim, pois Konder tem uma leitura aprofundada sobre ele e tem conhecimento de causa para afirmar tal questão.

Segundo o autor, o amor, para Marx, tem relação com o processo causado pela alienação do capitalismo. Mas esta informação não fica clara quanto aos argumentos que Konder usa para fazer esta afirmação. Konder aproveita e, como faz com todos os autores, oferece algumas notas biográficas sobre ele. Aqui, valem algumas peculiaridades que o autor levanta sobre os relacionamentos de Marx com sua esposa. Para Konder, Marx a amava, o que não o impediu que se apaixonasse e inclusive tivesse um filho em um caso extraconjugal. Nesse momento, ele aproveita para revelar sobre a trágica vida amorosa do famoso filósofo.

O texto, neste momento, oscila entre a teorização sobre o amor e o próprio sentimento vivido por ele e expresso através dos seus textos. Marx, segundo Konder, em o Capital, cita inclusive uma frase de Shakespeare: "o curso do verdadeiro amor nunca é sereno". Depois que a esposa de Marx morre, ele também.

Depois Konder passa por diversos autores, como já relatado anteriormente, mas talvez os principais citados pelo autor sejam Goethe e os brasileiros Guimarães Rosa e Carlos Drummond de Andrade.

Sobre o famoso poeta alemão Goethe, o autor apenas revela sua importante obra sobre o sofrimento do jovem Werther, que marca o romantismo alemão. Para Goethe, sem amor o sujeito não se completa. Amar é "mergulhar na alteridade" (p. 29). "O amor irrompe nas pessoas de maneira incontrolável. Ameaça a estabilidade da família, abala as hierarquias, pode destruir reputações" (p. 33). Vale dizer que, mais uma vez, o amor aparece, para os autores que Konder utiliza, como um sentimento, que, apesar de se apresentar pleno, é sempre incompleto e 
não realizável - algo que se apresenta como uma procura que nunca acaba.

É extremamente interessante que Konder apresente aquilo que os autores brasileiros pensam sobre o amor, já que, na maioria de textos sobre o assunto, apenas os clássicos são citados. Além disso, Konder aborda aspectos bastante interessantes do pensamento dos dois autores.

Sobre o brasileiro Guimarães Rosa, ele revela que este aponta o grande risco que existe de as pessoas se apaixonarem. Na sua obra, está presente o amor como desencontro. Quando ele aponta para o amor que não pode ser efetivado entre Riobaldo e Diadorim, no seu romanceGrande Sertão Veredas, como não lembrar de Romeu e Julieta e o amor que não se efetiva? Talvez estas marcas da literatura amorosa estejam na maior parte dos escritores que versam sobre o tema. Como não lembrar o clássico de Shakespeare? Portanto, não é à toa que a maior parte dos textos que Konder apresenta em seu livro esteja atrelada ao amor como desencontro ou sofrimento, uma vez que, como ele descreve, para Shakespeare o amor nunca se perpetua.

Sobre Drummond, Konder revela que o mineiro de Itabira se posicionava contra o capitalismo, como qualquer bom socialista, provavelmente, como o autor do livro. Fala do livro Amar se aprende amando e coloca este tipo de "sentimento" como uma prática, já precedendo o que autores como Bozon (2004) e Gagnon (2006) iriam abordar sobre o mesmo assunto décadas depois.

Foram realizadas aqui algumas pequenas observações sobre o livro, já que o texto de Konder aborda diversos autores que não poderiam ser citados todos nesta resenha. Mas vale algumas considerações sobre esta obra. Primeiro, Konder demonstra-se extremamente humilde, para quem tem tão importante reconhecimento intelectual no país. Segundo, esta obra não representa necessariamente um grande avanço conceitual sobre o tema, até porque, como o próprio autor revela, não foi esta sua preocupação. Ainda assim, ela consegue fazer o que se propõe: revisar vários autores, inclusive alguns que poucas pessoas suporiam falando sobre o amor, como Rosa Luxemburgo ou Fourier.

Konder teve a importante tarefa de desencadear a leitura de diversos textos importantes sobre o amor, o que já faz a obra valer a pena. Ele demonstra que, no alto de seus 70 anos intelectualmente bem vividos, ainda tem coragem de arriscar-se - capacidade esta que muitos intelectuais brasileiros já perderam e que talvez alguns nunca tenham tido. Ele é destemido, propõe-se a escrever sobre algo considerado de pouca relevância na academia ou nas ciências como a temática do amor. Além disso, faz sua análise a partir de uma perspectiva muito particular, pois demonstra, sem sombra de dúvida, que continua sendo e aplicando um dos primados ao seu pensamento: a capacidade de transformação, fundamental à crítica dialética. Konder continuou transformando, 
mantendo-se "fiel", palavra de forte sentido no discurso amoroso, ao seu princípio marxista.

\section{Referências Bibliográficas}

BAUMAN, Z. Amor Líquido: sobre a fragilidade dos laços humanos. Rio de Janeiro: Jorge Zahar Editor, 2004.

BLONDEL, E. L'Amour: textes cloisis \& presentes. Paris: Flammarion, 1998.

BOZON, M. Sociologia da sexualidade. Rio de Janeiro: FGV, 2004.

GAGNON, J. Uma interpretação do desejo: ensaios sobre o estudo da sexualidade. Rio de J aneiro: Garamond, 2006.

ROUGEMENT, D. História do amor no ocidente. São Paulo: Ediouro, 2003.

\section{Endereço para correspondência \\ Leandro Castro Oltramari \\ Endereço: Rua Antonio Schoroeder, 103, apto. 302, Barreiros, São J osé - SC \\ Endereço eletrônico: leandrooltramari@gmail.com}

Recebido em: 17/04/2008

Aceito para publicação em: 24/04/2008

Editor responsável: Ariane Patrícia Ewald

\footnotetext{
Notas

* Doutor em Ciências Humanas pela Universidade Federal de Santa Catarina-UFSC, Florianópolis, Santa Catarina, Brasil
} 